\title{
Representaciones sociales de Educación Religiosa en la media académica: una apuesta desde la virtualidad*
}

\section{Social representations of Religious Education in the academic media: a perspective from the virtual world}

\author{
Cetty Carlos Benjumea-Loaiza \\ Universidad de Córdoba, Montería, Colombia \\ Jesús Andrés Vélez-Vélez \\ Corporación Universitaria Lasallista, Caldas, Antioquia, Colombia
}

Open Access:

ISSN: $0124-2121$ E-ISSN: 2665-2420

\section{Resumen}

Objetivo: Describir las representaciones sociales que tienen los educandos de media académica de una Institución Educativa privada de Montería de la clase de Educación Religiosa. Método: La investigación se enmarcó en el enfoque cualitativo y el diseño de la doble hermenéutica, con técnicas como la cartografía social-pedagógica y el grupo focal, que, por la contingencia generada por el COVID-19 fueron aplicadas desde un entorno virtual. Resultados: Se evidenciaron las representaciones sociales que tienen los jóvenes sobre la clase de educación religiosa caracterizadas por ser un espacio confesional, asociado a la catequesis, que se plantea desde un modelo tradicional-transmisionista, fundamentado en el método escolástico y enfocado en la repetición de contenidos centrados en el cristianismo-católico; que además evade las perspectivas propuestas por los educandos; generando un sentimiento de opresión en estos últimos. Discusión y Conclusiones: A partir de los resultados, se presentó la necesidad de plantear un nuevo modelo de Educación Religiosa que permita a los educandos cultivar su identidad religiosa y desde ahí, estar en capacidad de entrar en diálogo con su realidad inmediata y mediata en términos de lo religioso; para desarrollar la capacidad de tomar postura frente a las diversas problemáticas religiosas contemporáneas que se le presentan.

Palabras clave: Cartografía social-pedagógica virtual, Educación Religiosa, grupo focal virtual, representaciones sociales, Significaciones, Creencias.

\begin{abstract}
Objective: To describe the social representations of Religious Education classes that private high school students in Monteria have. Method: The research was framed within the qualitative approach and the double hermeneutic design with techniques such as social-pedagogical mapping and the focus group, which were applied in a virtual environment due to the exceptional measures taken against Covid-19. Results: The social representations of the religious education classes that young people have, are characterized for being a confessional space, associated with catechesis, arise from a traditional-transmissionist model and based on the scholastic method and focused on the repetition of contents centered on Christianity-Catholic. Furthermore, religious education avoids the perspectives proposed by the learners; generating a feeling of oppression in the them. Discussion and Conclusions: The results revealed the need to propose a new model of religious education that allows the learners to cultivate their religious identity. This will enable students to engage in dialogues with their immediate and mediate reality in terms of religion to develop the ability to take a position in the face of the various contemporary religious issues to which they are exposed.
\end{abstract}

Keywords: Social representations, Religious Education, Virtual focus group, Virtual socialpedagogical mapping, meanings, beliefs.
ARTÍCULO DE INVESTIGACIÓN CIENTÍFICA Copyright (C)
By Educación y Humanismo

Editor:

Dhayana Fernández Matos
Correspondencia: cbenjumealoaiza35@correo.u nicordoba.edu.co

*Artículo de investigación científica derivado del proyecto de investigación "Emergencia de la conciencia histórica en educandos de la educación media académica a partir de un dispositivo didáctico en la clase de Educación Religiosa" financiado por los autores.

Cómo citar este artículo (APA): Benjumea-Loaiza, C. y Vélez-Vélez, J. (2021). Representaciones sociales de Educación Religiosa en

la media académica: una apuesta desde la virtualidad. Educación y Humanismo, 23(41), 119-137. https://doi.org/10.17081/eduhum.23.41.4921 


\section{Introducción}

La Educación Religiosa como saber escolar, se erige como un espacio pedagógico en el que se discurre sobre a asuntos que dan cuenta de la pregunta en torno al "¿Qué creer?, pregunta que está situada en relación con lo trascendente (el Misterio, el Absoluto, Dios mismo)" (Ministerio de Educación Nacional, 2014, p.24), lo que implica posicionarse frente a las experiencias de sentido que configuran la dimensión religiosa del sujeto desde los "tres ámbitos constitutivos de la noción de religión: la relación con el misterio, la búsqueda de sentido y la necesidad humana de autotrascendencia" (Meza y Suarez, 2013, p.19). Lo anterior, sitúa la clase de Educación Religiosa en los saberes que el educando y el maestro van conformando y que les permiten hacer una relectura de su dimensión religiosa como una realidad que aporta a su formación integral.

Sin embargo, la Educación Religiosa en Colombia, lejos de ser vista como el saber escolar definido en el párrafo anterior, ha sido y aún hoy es percibida como una herramienta de adoctrinamiento que sirve a un sistema de creencias particular y predominante en la escuela (Roa y Restrepo, 2014). Asimismo, se presenta "una serie de conflictos, discusiones, ambigüedades, imprecisiones y hasta equívocos que se han generado, en gran medida, como repercusiones de los intentos de poner en práctica el seguimiento de los principios, leyes y normas destinadas a regular esta área" (Beltrán, 2018, p.9). A lo anterior, se suma que la producción investigativa en este saber escolar es escasa aun cuando es un área obligatoria del plan de estudios la cual es bastante controversial y con problemáticas inherentes a la misma (Beltrán, 2018).

En línea con lo anterior, las investigaciones en Educación Religiosa evidencian que esta ha sido configurada como un espacio que se dinamiza a través de un modelo didáctico tradicional-transmisionista, con contenido repetitivos y prácticas evaluativas coercitivas que forma sujetos que nada saben sobre los rasgos básicos de las grandes religiones, no distinguen entre religión y hecho religioso, teísmo y agnosticismo y, aún menos, entre ateísmo e indiferentismo religioso; tampoco tienen una palabra que pronunciar sobre los acontecimientos religiosos nacionales y mundiales, cada vez más entrecruzados con los juegos políticos, las incidencias económicas, los procesos sociales y las necesidades emocionales de los ciudadanos (Echeverri, 2012; Meza-Rueda et al., 2015; Quintero, 2019; Roa y Restrepo, 2014; Saavedra y Tovar, 2015).

Con base en lo expresado anteriormente, se planteó esta investigación como una oportunidad para explorar a nivel de aula la forma en que los educandos comprenden y problematizan la Educación Religiosa, es por ello que se respondió al objetivo de describir las representaciones sociales de la clase de Educación Religiosa que tienen los educandos de media académica de una Institución educativa de carácter privado de la ciudad de Montería, esto, teniendo en cuenta que en la medida que ellos van ascendiendo en su grado 
de escolaridad se hace más frecuente la desmotivación y la indiferencia frente a la clase porque no responde a sus expectativas, intereses ni experiencias de vida por lo que es necesario identificar, interpretar y evaluar la significatividad de la Educación Religiosa en su desarrollo personal (Castaño, 2018; Rossiter, 2010).

Debido a la cuarentena decretada por el gobierno nacional en respuesta a la emergencia sanitaria ocasionada por la pandemia del COVID-19, se optó por hacer el trabajo de campo de manera virtual.

\section{Referentes teóricos}

Es innegable que la religión es una parte esencial de la cultura, de todo aquello que hace que uno sea como es a nivel personal y colectivo, otorgando sentido a la existencia humana, por lo tanto, acercarse a esta implica ahondar en su universo simbólico (Coy, 2009). De ahí que se opta por las representaciones sociales para dicho acercamiento, pues se convierten en la clave de lectura que traduce el simbolismo propio de la religión y por consiguiente de la Educación Religiosa, en el lenguaje concreto de tales representaciones.

\section{Representaciones sociales}

Serge Moscovici (1979) define las representaciones sociales como "una modalidad particular del conocimiento, cuya función es la elaboración de los comportamientos y la comunicación entre los individuos" (p.17), por lo que, se pueden configurar como una modalidad epistémica que convierte los constructos de sentido común de los distintos grupos sociales, en un saber que se legitima en tanto que da cuenta de una realidad particular puesto que, estas representaciones "no son sólo opiniones, imágenes o actitudes, son formas de conocimiento que contribuyen al descubrimiento y la constitución de la realidad" (Quintero, 2019, p.72).

En este sentido, se presentan las representaciones sociales como el resultado de la indagación de las significaciones y creencias que tienen los educandos en torno a la clase de Educación Religiosa ya que, estas dos categorías permiten la conformación del núcleo figurativo y el campo de representación que, como afirman Castorina y Barreiro (2012), ayudan a salvaguardar fisuras culturales provocadas por los vacíos sociales de los que emergen las representaciones; porque las significaciones se definen como un sistema que interpela el curso de los acontecimientos y las relaciones sociales; que expresan la relación que los individuos y los grupos mantienen con el mundo y los otros (Jodelet, 2000), y las creencias se configuran como "las disposiciones del otro [que] me comunican acerca de un mundo que puede ser común con el mío, las califico de 'objetivas'"' (Villoro, 2007).

Ahora bien, la descripción de las representaciones sociales implica que el investigador se sitúe desde un enfoque particular ya que estas pueden ser estudiadas desde un enfoque 
estructural, de corte cuantitativo (Abric, 2001), o bien, desde el enfoque procesual, orientado al enfoque cualitativo Spink (1994 citado en Banchs, 2000). A partir de lo anterior, es importante mencionar que esta investigación se situó en el enfoque procesual en tanto que, teniendo en cuenta, el fenómeno abordado, el método en el que se inscribe y las técnicas de recolección de la información, se buscó seleccionar y descontextualizar la información dispersa referente al fenómeno, para la conformación del núcleo figurativo en el que emergió una imagen estructurada de los conceptos abstractos, lograda por la presión a la inferencia en el grupo social, que desembocó en la naturalización del objeto de estudio el cual se ancló en las creencias y significaciones de los sujetos.

\section{Educación Religiosa}

En la búsqueda de la respuesta a la pregunta por el qué creer, la Educación Religiosa se fundamenta en los ámbitos constitutivos de la noción de religión, los cuales se abordarán a continuación, a la vez que intenta entrar en diálogo con las otras disciplinas en tanto que se indaga por esta respuesta. Cada uno estos ámbitos tienen unas características que brindan una orientación particular en la clase.

\section{Relación con el misterio}

La palabra misterio, generalmente, alude a aquello que es desconocido o que no tiene explicación y hablar de ello en el plano de lo religioso, orienta al sujeto a pensar en elementos propios de lo esotérico y exotérico; sin embargo, aunque lo dicho puede tener validez y aceptación, este concepto en lo religioso va más allá pues, es entendido como la categoría interpretativa con la que designamos lo que tienen de común todas las formas de divinidad, es decir, todas las configuraciones que el sujeto ha dado de lo que es el término de su actitud religiosa. El Misterio es el nombre para la divinidad en el que todas las formas de la misma coinciden $y$, por tanto, aquel en el que se reconocerán todos los sujetos religiosos; aquel que resume y explica la nueva forma de ser que reciben los objetos afectados por lo sagrado. (Velasco, 2006, p.125).

Por lo tanto, el misterio orienta las experiencias religiosas que vive el sujeto haciendo de él, un ser religioso, es así como emerge el ámbito de lo sagrado el cual Eliade (1999) define como "la diferencia entre lo que se manifiesta como real, fuerte y rico en significado, y lo que aparece desprovisto de estas cualidades" (p.17).

A partir de esta dinámica mistérica, el maestro y los educandos se dan encuentro en un ambiente escolar en el que el misterio ya no refiere a la imagen del Dios personal, exclusivo de las religiones reveladas, sino que se ancla en el orden de la experiencia de sobrecogimiento que vive el sujeto al sentirse abarcado por el Totalmente otro, al cual es incapaz de asignarle ninguna categoría ya que supera su entendimiento (Velasco, 2006). Es así como se configura la actitud religiosa que posibilita una lectura desde lo trascendente como posibilidad de reflexión, donde maestro y educando problematizan sus cosmovisiones, 
sistemas de creencias y escalas de valores; con miras a constituir el centro de sus vidas desde lo que realmente importa, para interpretar los momentos estructurantes de su historia.

\section{Necesidad humana de autotrascendencia}

La relación con el misterio, hace brotar en el sujeto la necesidad humana de autotrascendencia porque a partir de ella, surge el impulso de compartir con el otro y lo otro las experiencias de sentido que han sido configuradas en este encuentro inicial, impulso que lo orienta a buscar el bien no como un acto del "placer o del dolor, ni acerca del confort o de la incomodidad, ni acerca de la espontaneidad sensitiva, ni de las ventajas individuales o de grupo, sino acerca del valor objetivo" (Lonergan, 2006, p.106), sino como una manera de ser auténticamente humano.

Ahora bien, este movimiento siempre será en salida "porque por muy personal e íntima que sea la experiencia religiosa, no es solitaria" (Lonergan, 2006, p.119), por ello la necesidad de preguntarse quién es el otro y cómo entra en relación con él. La primera tarea de la Educación Religiosa en este ámbito implica el imperativo de que el sujeto pueda identificar desde su experiencia religiosa, la manera en que se relaciona con los otros y así establecer intenciones y propósitos que lo hagan parte de una comunidad.

También es importante señalar que en este ámbito, la religión debe llevar a reconocer y valorar la relación con el entorno y la historia, porque esta se transforma en una dimensión que permite dar respuesta a los interrogantes profundos del ser humano, justifica muchas de sus conductas y se convierte en clave hermenéutica de la vida social, cultural, artística, histórica y trascendental de las personas y las sociedades (Coy, 2009), por tanto, insta al sujeto asumir posición crítica frente a los acontecimientos que ocurren en su contexto pues, lo religioso hace parte del sustrato cultural del hombre, por ello es necesario posibilitar espacios de interrogación en torno a qué le dice la religión a cada uno de los acontecimientos sociales que ocurren a su alrededor y a partir de ahí, construir claves de lectura para discernir las realidades que ocurren en su entorno.

\section{Búsqueda de sentido}

Este tercer ámbito, apunta a la consideración de la experiencia religiosa como un modo más profundo de vivir la realidad que surge en la vida misma, lo que lleva a la persona a descubrir una experiencia de sentido desde la cual emerge la lectura consciente de lo vivido hasta el nivel del misterio y la apertura trascendente, justificando así la búsqueda de respuestas a interrogantes como quién soy, de dónde vengo, para dónde voy, qué significado tiene la vida; entre otras que conforman el mundo de la interioridad (Sotomayor, 2003), dando origen a lo que Pikaza (1999) considera como una experiencia creadora de sentido que confiere hondura a las distintas dimensiones de la vida humana desde la apertura al cosmos y a la historia, lo que permite dar sentido a la realidad. 
Ahora bien, los 3 ámbitos de la Educación Religiosa, incluso el área escolar misma, no son dinamizados desde un posicionamiento neutro, más bien parten de un modo de comprensión de la realidad y el objetivo que se traza el maestro en las situaciones didácticas, las cuales han originado tres modelos de legitimación de este saber escolar.

\section{Modelo de legitimación de la Educación Religiosa a partir de la misión de la Iglesia}

Debido a la carga histórica que ha recibido la educación en Colombia de parte de la Iglesia católica gracias a la autoridad que le confirió la constitución política de 1886 de regular la educación, se dieron las condiciones ideales para que la Educación Religiosa estuviera orientada hacia la tarea evangelizadora, la cual se dinamizó desde el método escolástico, en el que primaba la lectio como estrategia didáctica para la memorización de unos saberes de naturaleza dogmática, que concebía a los educandos como pequeños catecúmenos y, aunque esto cambió con la constitución de 1991, aún se asocia este saber escolar con la catequesis (Meza y Suarez, 2013).

\section{Modelo de legitimación de la Educación Religiosa a partir de la dimensión religiosa del ser humano}

Este modelo de legitimación, parte del principio de que la dimensión religiosa es fundamental para la existencia humana, es por ello que, la Educación Religiosa se propone aportar pistas para responder a las preguntas por el sentido y, en consecuencia, por el sentido último (Meza y Suarez, 2013). Desde lo anterior, se plantea un modelo orientado al descubrimiento de la dimensión religiosa que promueve la relación con el misterio para comprender las experiencias existenciales de la persona, así como la relectura de la realidad desde su tradición religiosa. Los contenidos están dados por los estudios de la religión que permiten al sujeto decidir frente a asuntos propios de su vida creyente y religiosa, además implementa estrategias didácticas que fomentan el desarrollo del sentido crítico, desde mediaciones como el texto sagrado, entendido como "un material experiencial-didáctico que facilita la comprensión acerca de la manera como Dios actúa en la historia de la humanidad" (Meza y Suarez, 2013, p.56). Parra (2007, citado en Meza y Suarez, 2013) plantea la evaluación desde la adquisición de competencias orientadas al "saber ser, saber vivir, saber ser en comunidad, saber leer y escribir el texto grande de la vida, saber ser en libertad y en comunidad" (p.57) y creer con responsabilidad.

\section{Modelo de legitimación de la Educación Religiosa a partir de la cultura}

El modelo de legitimación de la Educación Religiosa desde la cultura, se orienta a la comprensión de la propia tradición religiosa, así como de las otras tradiciones, por ello los contenidos que se abordan deben responder al "conocimiento de las diversas religiones y sistemas de valores presentes en el ambiente. Por supuesto, como nuestra cultura es marcadamente cristiana, el cristianismo será un tema obligado y recurrente pero no 
exclusivo" (Meza, 2012, p.32). Asimismo, Los métodos se orientan al reconocimiento de la diferencia para la construcción de comunidad; porque la religión debe permitir al sujeto poder ubicarse con respecto a lo religioso y lo que implica la influencia de este en la realidad (Coy, 2009).

\section{Metodología}

Este trabajo se sitúa en el paradigma interpretativo en tanto que, intenta comprender la realidad desde las creencias, valores y reflexiones de los sujetos, para construir teorías prácticas, configuradas a partir de las peculiaridades de la cotidianidad (Ricoy, 2006). Así mismo, esta investigación se inscribe en un enfoque cualitativo, el cual es definido por Dorio et al. (2009) como una aproximación a un fenómeno para adquirir una perspectiva del mismo desde la descripción y comprensión de las acciones y relaciones que se dan en un contexto particular y así lograr la transformación y por consiguiente, la mejora social.

Además de lo ya dicho, también es importante mencionar que la doble hermenéutica fungió como diseño metodológico de esta investigación, ya que permitió "interpretar hechos ya interpretados por los sujetos sociales y a la posibilidad de reintegrar los productos de la investigación en esos mismos marcos de interpretación" (Fuentes, 2014, p.56), lo que se logró a partir de la construcción de las representaciones sociales de los educandos, que dieron lugar a los marcos interpretativos, que luego fueron abordados por los investigadores, para destacar los elementos que configuraban el vacío social, expresados en las significaciones y creencias en torno a la Educación Religiosa; logrando el doble movimiento propio de este diseño metodológico.

\section{Participantes}

La población de la investigación estuvo constituida por 243 educandos ubicados en los grados $10^{\circ}$ y $11^{\circ}$ de la institución educativa de carácter privado de la ciudad de Montería donde se realizó el estudio, de estos participaron 52, los cuales fueron distribuidos en 7 grupos a los que se aplicaron las técnicas de recolección de la información grupales como la cartografía social-pedagógica y el grupo focal, que, por el confinamiento decretado por el gobierno nacional, debido a la emergencia sanitaria provocada por la pandemia de COVID19, fueron aplicadas en un entorno virtual. Se debe tener en cuenta que en la virtualidad Schneider et al. (2002, citado por Bordini y Sperb, 2011) sugieren que pueden haber de 6 a 12 participantes por ello los grupos conformados oscilaron entre 6 y 8 participantes.

\section{Técnicas de recolección de la información}

Teniendo en cuenta los grupos conformados y el diseño metodológico, se optó por dos técnicas de recolección que permitieron recabar la información requerida. La primera de ellas fue la cartografía social-pedagógica que permitió el abordaje de las representaciones sociales de los educandos de la clase de Educación Religiosa, luego para la profundización 
de los aspectos señalados en esta y para hacer emerger aquellos elementos que pudieron haber escapado al primer ejercicio, se procedió con el grupo focal.

Es importante mencionar que, como sugieren Bordini y Sperb (2011) con respecto al grupo focal, las técnicas de recolección de la información de carácter grupal en la virtualidad no son una mera transposición de sus contrapartes presenciales, pues estas conllevan sus especificidades ya que, emergen ante la imposibilidad de los encuentros cara a cara, además es importante garantizar el manejo de las herramientas virtuales por los participantes. En este sentido, el trabajo de campo se desarrolló a través de la aplicación de videoconferencias ZOOM y los mapas temáticos de las cartografías sociales-pedagógicas se hicieron a través del aplicativo de Google dibujos.

Antes de iniciar el trabajo de campo, fueron requeridos los consentimientos y asentimientos informados, los cuales ya habían sido facilitados a los educandos y sus acudientes; momento siguiente, se fijó fecha y hora de los encuentros, información que fue enviada a los correos de los educandos y sus acudientes, junto con los objetivos y el protocolo de entrada al encuentro sincrónico.

Para la ejecución de la cartografía social-pedagógica virtual, el investigador y los participantes, quienes se identificaron con un código o nickname para proteger su identidad, se dieron encuentro en la plataforma ZOOM. El moderador presentó el ejercicio y las orientaciones a tener en cuenta para la interacción. Téngase en cuenta que, la cartografía social-pedagógica como estrategia de investigación, busca que, a través de la acción colectiva, los participantes reflexionen sobre sus comprensiones en torno a una problemática común y la evidencien a través del levantamiento de un mapa en el que se cartografía un territorio existencial, relacionado con las tensiones de las prácticas de enseñanzaaprendizaje (Barragán, 2016). En este caso, La problemática común estuvo costituida por las representaciones sociales de la clase de Educación Religiosa, las cuales tomaron forma a través del mapa temático en el que los educandos expresaron su comprensión de la clase en términos de fortalezas y debilidades, que se convierten en posibilidades de transformación de la misma (Barragán y Amador, 2014).

Lo anterior, se operacionalizó a través de la aplicación de un taller de cartografía socialpedagógica que indagó por las significaciones y creencias en torno a esta clase a través de unas preguntas orientadoras (tabla 1) que orientaron la discusión.

Tabla 1

Preguntas orientadoras taller de cartografía social-pedagógica

\begin{tabular}{|c|c|c|}
\hline Categoría & Subcategoría & Pregunta orientadora \\
\hline \multirow{2}{*}{$\begin{array}{l}\text { Representaciones } \\
\text { sociales }\end{array}$} & Significaciones & $\begin{array}{l}\text { Si la clase de Educación Religiosa fuera un lugar, escenario } \\
\text { o ambiente, ¿cuál sería? }\end{array}$ \\
\hline & Creencias & $\begin{array}{l}\text { 1. ¿Qué saberes de la clase de Educación Religiosa que } \\
\text { destacamos? Le asignamos un símbolo a cada uno de ellos }\end{array}$ \\
\hline
\end{tabular}


2. ¿Qué saberes de la clase de Educación Religiosa que no se dan en esta incluiríamos? Le asignamos un símbolo a cada uno de ellos.

3. Las estrategias didácticas que se han usado en la clase de Educación Religiosa. Le asignamos un símbolo.

Fuente: Elaboración propia (2021)

Luego de la discusión generada a partir de las preguntas orientadoras, se propuso a los educandos la construcción del mapa temático, en torno a la clase de Educación Religiosa, a través de los símbolos acordados para las significaciones y creencias de la misma. Finalmente, se procedió con las líneas de relación (figura 1), las cuales tenían una doble función, por un lado, determinar las actitudes frente a la clase y, por otro, describir a qué tipo de ámbito de la religión apuntaba el saber o estrategia didáctica propuestos.

Figura 1

Convenciones de líneas de relación

\section{Convenciones según el tipo de relación}

1. Saberes que me ayudan a responder preguntas como por qué estoy aquí, por qué vivo, qué significado tiene la vida, que es la muerte.

2. Saberes que me ayudan a comprender las distintas religiones.

3. Saberes que expresan la relación sociedad-religión.

4. Saberes que me ayudan a comprender mi relación con los otros.

5. Saberes que me ayudan a comprender mi relación con Dios

6. Saberes que me ayudan a comprender mi relación con el entorno que

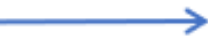
me rodea

7. Estrategias didácticas que facilitan la adquisición de saberes en la clase de educación religiosa.

8. Estrategias didácticas que difícultan la adquisición de saberes en la clase de educación religiosa.

Elaboración propia (2021)

En un segundo momento, se conformó un grupo focal que buscó "analizar la interacción entre los participantes y cómo se construyen significados grupalmente" (Hernández et al., 2010, p.426). Desde "el abordaje a fondo de un número muy reducido de tópicos o problemas" (Sandoval, 1996, p.145). Por ello, con esta técnica se profundizó en los constructos de las cartografías sociales-pedagógicas. En la aplicación de esta técnica, como en la cartografía, se asignó un código o nickname a los educandos.

La técnica se desarrolló en dos segmentos, el primero orientado a complementar lo presentado en la cartografía y el segundo momento indagó por cómo debería ser esta clase (tabla 2). 
Tabla 2

Preguntas orientadoras grupo focal

\begin{tabular}{|c|c|c|}
\hline Categoría & Subcategoría & Pregunta orientadora \\
\hline \multirow{2}{*}{$\begin{array}{l}\text { Representaciones } \\
\text { sociales }\end{array}$} & Significaciones & $\begin{array}{l}\text { 1. ¿Para ti qué es la clase de Educación Religiosa? } \\
\text { 2. ¿Cómo crees que debería ser la clase de Educación } \\
\text { Religiosa? } \\
\text { 3. ¿Qué cambiarías de la clase de educación religiosa si } \\
\text { tuvieras la oportunidad? }\end{array}$ \\
\hline & Creencias & $\begin{array}{l}\text { 1. ¿Cuál debe ser su objetivo final? } \\
\text { 2. ¿Desde qué ejes temáticos se debe estructurar? } \\
\text { 3. ¿Qué estrategias y modos de evaluación debe tener en } \\
\text { cuenta? }\end{array}$ \\
\hline
\end{tabular}

Fuente: Elaboración propia (2021)

\section{Resultados}

A partir de la información recolectada en las cartografías sociales-pedagógicas, se conformaron los mapas temáticos (figura 2), con sus respectivas convenciones (tabla 3), que dieron cuenta de las representaciones sociales de los educandos en torno a la educación Religiosa. Los 7 mapas temáticos construidos por los grupos, dieron cuenta de las significaciones y creencias que configuran estas representaciones.

\section{Figura 2}

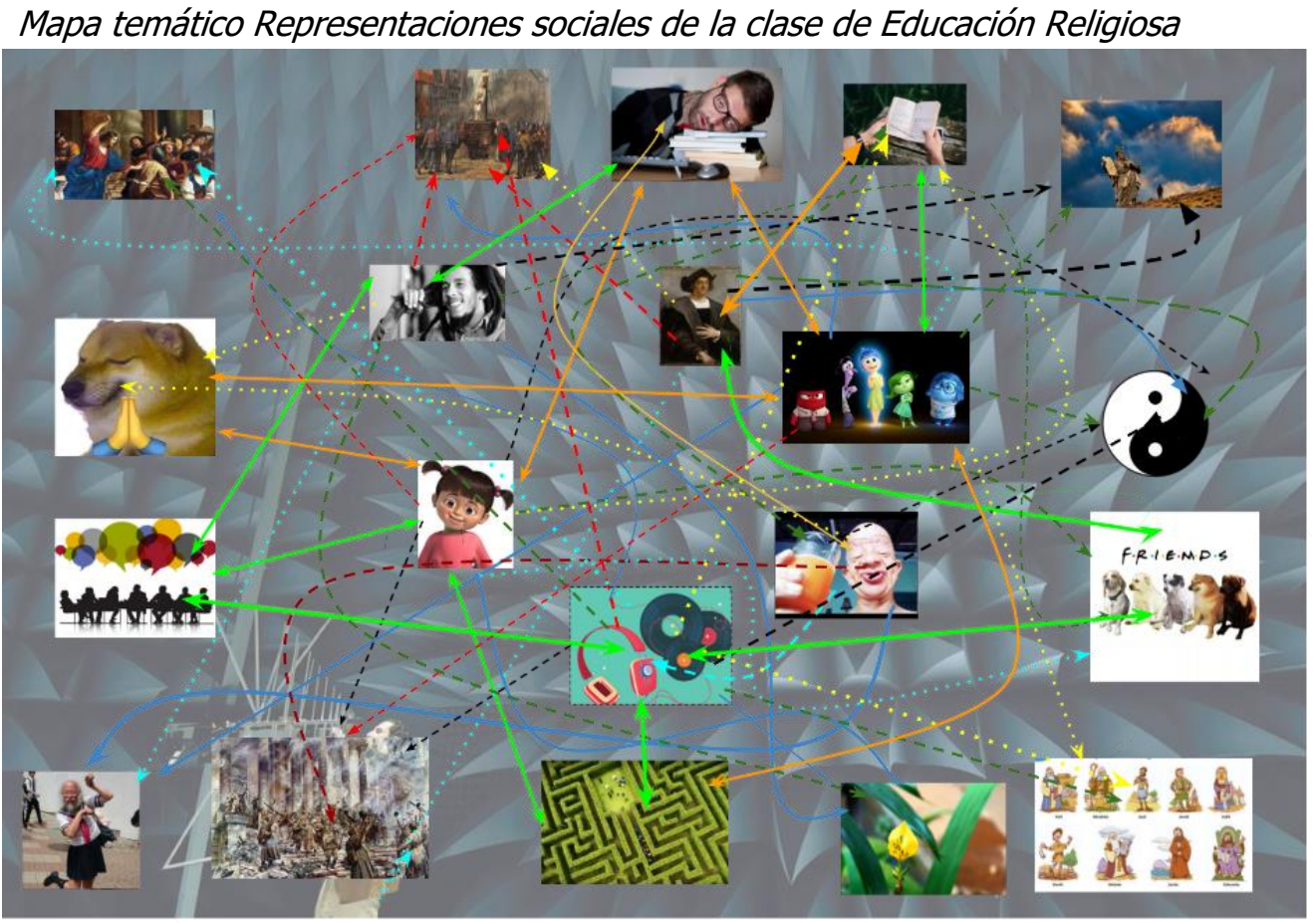

Fuente: Elaboración propia (2021) 


\section{Tabla 3}

Convenciones del mapa temático

\begin{tabular}{|c|c|c|c|c|c|c|}
\hline \multicolumn{7}{|c|}{ Tabla de convenciones } \\
\hline $\begin{array}{l}\text { Saberes de } \\
\text { la clase de } \\
\text { ER }\end{array}$ & $\begin{array}{l}\text { La vida de } \\
\text { Jesús }\end{array}$ & $\begin{array}{l}\text { Mandamient } \\
\text { os }\end{array}$ & $\begin{array}{l}\text { Pecados } \\
\text { capitales }\end{array}$ & $\begin{array}{l}\text { Nacimiento } \\
\text { de Jesús }\end{array}$ & & \\
\hline $\begin{array}{l}\text { Saberes que } \\
\text { no se } \\
\text { abordan en } \\
\text { la clase de } \\
\text { ER }\end{array}$ & $\begin{array}{l}\text { Religiones } \\
\text { distintas a la } \\
\text { católica }\end{array}$ & $\begin{array}{l}\text { Personajes } \\
\text { bíblicos } \\
\text { (antiguo } \\
\text { testamento) }\end{array}$ & $\begin{array}{l}\text { Ifol } \\
\text { Influencia } \\
\text { de la } \\
\text { religión en } \\
\text { la historia }\end{array}$ & $\begin{array}{l} \\
y+19 \\
\text { Creencias } \\
\text { de los } \\
\text { antepasados }\end{array}$ & & \\
\hline $\begin{array}{l}\text { Estrategias } \\
\text { de la clase } \\
\text { de ER }\end{array}$ & La eucaristía & $\begin{array}{l}\text { Mesa } \\
\text { redonda }\end{array}$ & $\begin{array}{l}\text { Plan de } \\
\text { clase }\end{array}$ & $\begin{array}{l}\text { Lectura de } \\
\text { la palabra }\end{array}$ & $\begin{array}{l}\text { f.R.temp.s } \\
\text { g. } \\
\text { Trabajo en } \\
\text { grupos }\end{array}$ & $\begin{array}{l}\text { Crucigrama- } \\
\text { sopa de } \\
\text { letras }\end{array}$ \\
\hline $\begin{array}{l}\text { Símbolo del } \\
\text { educando }\end{array}$ & Est.15 & Est. 16 & Est. 17 & Est. 18 & Est. 19 & $\begin{array}{l}\text { AIf } \\
\text { Est. } 20\end{array}$ \\
\hline
\end{tabular}

Fuente: Elaboración propia (2021)

A su vez, los grupos de discusión y las reflexiones generadas que dieron lugar a los mapas temáticos, fueron analizados a través del software de análisis cualitativo Atlas.ti, arrojando una red semántica (figura 3) que permitió complementar y legitimar los hallazgos de las cartografías sociales-pedagógicas.

Figura 3

Red semántica de las representaciones sociales de la clase de Educación Religiosa

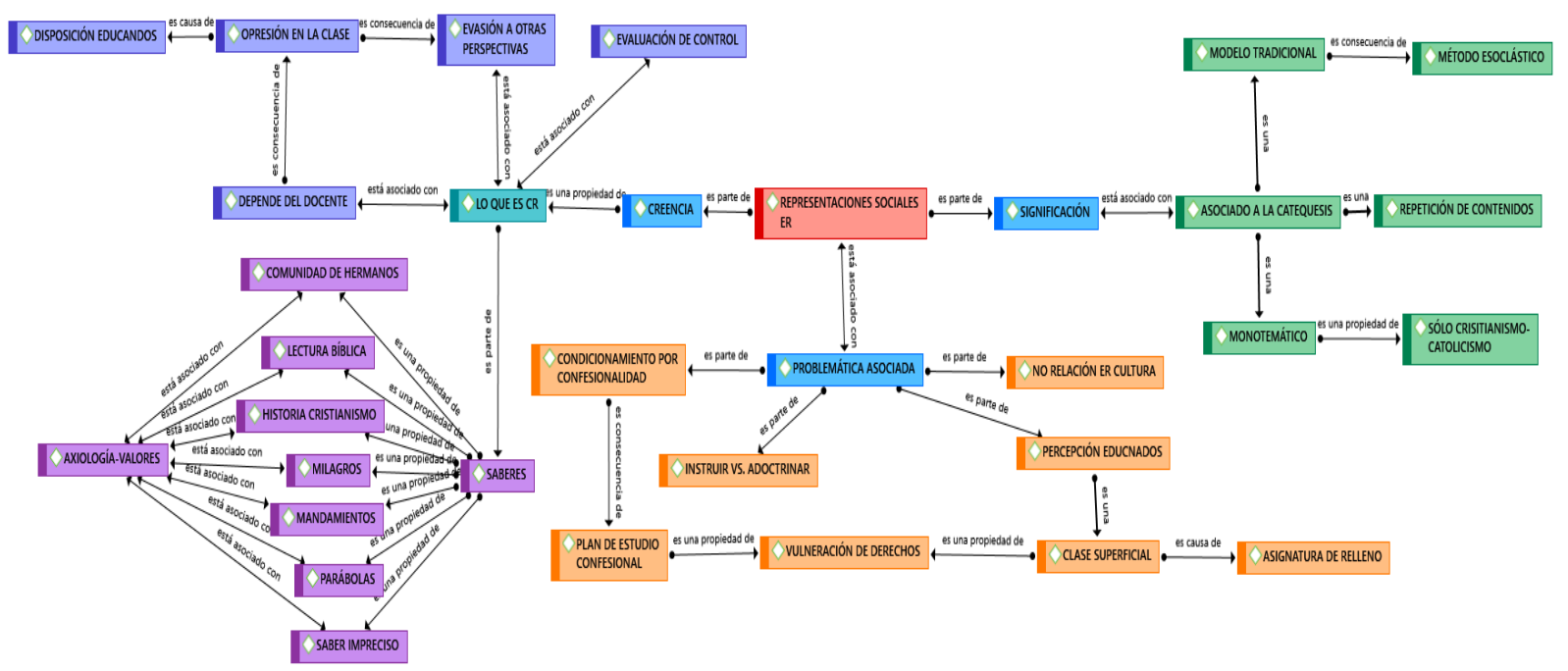

Fuente: Elaboración propia (2021) 
En este sentido, se presentan en este apartado las significaciones y creencias que dan cuenta de estas representaciones.

\section{Significaciones}

Para el abordaje de las significaciones que configuran las representaciones sociales de la clase de Educación Religiosa, se exploraron las imágenes de fondo propuestas en cada uno de los mapas temáticos que dan cuenta de las características que los educandos atribuyen a esta clase. Por ejemplo, el mapa temático del grupo $N^{\circ} 1$ (Figura 2) muestra como imagen de fondo una cámara anecoica, que es un cuarto donde se absorbe el mayor ruido posible, dentro de ella no se escucha nada por lo que se siente una constante tensión porque nada fluye, así ocurre en la clase pues la definen como un espacio donde no se hace nada o siempre se aborda el mismo plan de clase con los mismos temas, o como mencionó SigcartG1E31: cuando tú estás en esa clase lo que tú haces, es hacer nada, solamente lo que el profesor quisiera que uno hiciera y eso es una cámara anecoica.

Por su parte, el grupo №2 representó la clase de Educación Religiosa con un bus viejo y oxidado porque para ellos la clase es un momento monótono en el que a pesar de ser un espacio pedagógico que genera la posibilidad de gran riqueza para explorar elementos concernientes a la relación con Dios, la diversidad religiosa y la relación de la religión con la vida cotidiana; esta siempre termina girando en torno a las mismas temáticas y a través de las mismas estrategias didácticas orientadas desde el modelo catequético, como ocurre con los autobuses que siguen las mismas rutas todos los días.

De igual forma, el grupo $\mathrm{N}^{\circ} 3$ representó la clase con un salón con libros y sillas, haciendo referencia a que, como lo mencionó SigCartG3E16 en la discusión inicial de la cartografía, ahora mismo, lo que me está dando la clase de religión sería más o menos una educación de lo que hay en la Biblia en sí pero no me está enseñando a establecer una conexión con Dios, por así decirlo que es para lo que debería ser la religión. Es prácticamente como una sociales, pero de religión, evidenciando que los ámbitos constitutivos de la religión no se tienen en cuenta, por lo que la clase se convierte en un espacio vacío como lo dejó ver SigCartG3E16. Por otro lado, el grupo N4 asocia la clase de Educación Religiosa en su mapa temático con una amalgama de imágenes conformada por una capilla blanca, unos pocos niños, dos libros y unas cadenas que describen lo que los educandos de este grupo expondrán a continuación

SigCartG4E26: una capilla blanca con sus elementos y con dos tonos de blanco, uno más oscuro para que represente que siempre es lo mismo y el más claro para que represente, la pureza del profesor, así creamos un solo ambiente con las tres percepciones.

\footnotetext{
${ }^{1}$ Código usado para resguardar la identidad del participante de la investigación según los principios éticos que orientaron la misma, este significa Significación cartografía grupo 3 estudiante 16
} 
SigCartG4E24: la clase de religión, la comparo con unos cuantos estudiantes y unas pocas sillas porque en mi salón somos muchos, pero sólo algunos participamos y los demás no están prestando atención.

SigCartG4E25: se pueden añadir dos libros que signifique que nos esforzamos más por leer cosas y no aprender, cómo que las clases de religión son súper aburridas.

SigCartG4E27: podríamos poner cadenas por mostrar que se siente como una obligación porque a mí, por ejemplo, no me nace hacer la clase, entonces yo pondría cadenas para simbolizar la obligación que se siente porque no creo que sea el único.

El grupo $N^{\circ} 5$, en su mapa temático presenta la clase como un desierto en el que el sol representa al sistema de creencias cristiano-católico como el único que se enseña en la clase y que, además es enseñado de manera superficial; dicha superficialidad es simbolizada con la arena, que impide llegar a la riqueza del agua o petróleo que en la representación refiere a la diversidad religiosa y la capacidad crítica que la clase debería generar en los educandos. En este desierto hay dos personas caminando, con la particularidad de que cada una habla un idioma distinto, estas simbolizan al maestro y al educando que van en una sintonía distinta en medio de la clase, lo que hace que no se comprendan entre sí porque mientras el maestro habla desde su perspectiva cristiano-católica, los educandos no pueden expresar sus posturas en la clase

SigCartG5E33: yo lo veo más representado como un desierto precisamente porque tómese el desierto, el sol como lo único que nos enseñan, cómo lo dijo 34 Qué sólo se basan en lo católico y el catolicismo y véase la arena como la capa que separa a lo que es importante como es el petróleo en la representación, que son la diversidad y las críticas de las diferentes religiones que es lo que en serio nos deberían explicar.

SigCartG5E30: lo compararía con dos personas que no hablan el mismo idioma, entre ellos pueden estar diciéndose muchas cosas y no se entienden, porque nosotros nos guardamos las cosas que quisiéramos decir y eso pasa con la clase.

El mapa temático del grupo $\mathrm{N}^{\circ} 6$, en sintonía con lo expresado por los grupos anteriores, opta por la imagen de un carrusel porque para ellos la clase de Educación Religiosa está representada por unos caballos que todo el tiempo están dando vueltas en el mismo sentido y además tienen unas cinchas en los ojos no les permiten ver hacia otros lugares, puesto que la clase de Educación Religiosa no se conecta con la realidad, así como lo explica SigCartG5E35: se puede considerar la idea de los caballos que van en los Carruseles, ellos tienen unas cinchas para ver solamente al frente, entonces la imagen se podría considerar el Carrusel y que nosotros somos los caballos que solamente vamos hacia delante o dando vueltas porque seguimos un camino, solamente de lo que nos quieren mostrar, de lo que les conviene mostrarnos y no toda la realidad, todo lo que involucra a seguir de lo que se habla en esa clase. 
Finalmente, el mapa temático del grupo $\mathrm{N}^{07}$ representa la clase con un océano, que, como los grupos anteriores, insiste en la superficialidad y "monotematicidad" de la clase (Meza-Rueda et al 2015; Roa y Restrepo 2014), que en palabras de SigCartG7E48, significa que la clase es un océano porque se enseña lo que ya se conoce, sin embargo hay un trasfondo que debería darse a conocer más profundamente, porque en la clase sólo dan a conocer lo que se cree, pero hay mucho detrás de ello como la vocación que trae la religión porque por mucho tiempo la religión fue considerada como una doctrina y no como algo que uno debería ser por vocación.

Ahora bien, todo lo ya expresado, de manera dispersa, en las significaciones que hacen parte de las representaciones sociales de los educandos, se ve validado y legitimado en los hallazgos que arrojó la red semántica (figura 3), fruto de los grupos de discusión y las reflexiones generadas alrededor de la construcción de los mapas temáticos. Para los educandos, la clase es un espacio pedagógico de adoctrinamiento, en tanto que sólo se problematiza el sistema de creencias cristiano católico, lo que termina por convertirla en un espacio catequético SigCartG7E47: instruirte en una sola perspectiva y no abrir tu panorama a otros medios y otras perspectivas como debería ser; además, se dinamiza desde un método escolástico, que, como plantean (Meza y Suarez, 2013) se centra en el aprendizaje de verdades dogmáticas que deben ser aprendidas de memoria a partir de la lectura bíblica.

Aunado a lo dicho en el párrafo anterior, se destaca la monotematicidad de la clase en tanto que, como ya se dijo, sólo se abordaba un sistema de creencias y cuando los educandos tocaban asuntos distintos a este, el maestro se encerraba y evadía estas perspectivas SigCartG5E35: el profesor se encerraba solamente en su opinión y no hablamos de otras cosas. No obstante, no se trata de sacar al cristianismo de los programas de formación en Educación Religiosa, porque este, inevitablemente hace parte de la cultura (Meza, 2012) antes bien, se debe plantear este contenido temático desde una posición crítica que permita entenderlo desde lugares distintos a la confesionalidad.

\section{Creencias}

A la par de las significaciones, emergieron las creencias, con las cuales se configuraron las representaciones sociales en torno a la clase de Educación Religiosa. La primera de ellas, se centra en los saberes que los educandos destacaron de su clase, entre ellos destacan los mandamientos, que también aparece en 6 de las cartografías; las parábolas, aparece en 3 cartografías; los milagros, la lectura bíblica, que aparece en 5 cartografías; así como la comunidad de los Hermanos y la historia del cristianismo; todo ello orientado desde lo cristiano-católico y con un direccionamiento hacia los valores más que a la búsqueda de respuestas a la pregunta del qué creer, validando lo que Meza-Rueda et al. (2015) proponen como la permutación de la Educación Religiosa por la formación en valores.

Ahora bien, cuando se indaga entre los participantes del porqué destacan estos contenidos, responden que los mismos dependen del maestro, como lo dice CrGrup6E39: lo 
que él hacía era más enfocarse en su opinión del catolicismo y ya, situación que les trasmitía la imposibilidad de plantear perspectivas distintas a la establecida y, más allá de esto, se generaba un ambiente de opresión en el cual los educandos sentían que no podían expresar su opinión CrCartG2E11: ponen a personas que expliquen una clase de religión, pero no nos dejan ser libres. Nuestra expresión, nuestro pensamiento durante una clase de religión es mínimo es muy rara vez que un profesor de religión sale de sus límites o de su comodidad, Incluso hasta el punto de tener la evaluación como una estrategia más para validar esta evasión (Saavedra y Tovar, 2015).

En línea con lo expresado en el párrafo anterior, la evaluación además de ser un mecanismo condicionante, también se percibía como coercitivo ya que, además de no permitir que se expresaran perspectivas distintas a lo establecido, lo que se socializaba en clase era evaluado para controlar el cumplimiento más que para problematizar la dimensión religiosa de los educandos o comprender de una mejor forma el componente cultural que hace parte de la dimensión religiosa. CrGrupG3E21: cuando una persona hacía una intervención un poco distinta o tenía una perspectiva de la religión diferente era como cerrado en ese aspecto. Cuando uno le hacía una pregunta con respecto a un tema que tenía que ver con la religión y el impacto en la sociedad desde otro punto de vista que no fuera el católico él era bastante restringido con sus respuestas, como que no estaba de acuerdo.

\section{Senderos por transitar}

Ante el panorama expuesto a partir de las representaciones sociales en torno a la Educación Religiosa, se hace necesario que este saber replantee su forma de concebirse en la escuela ya que, el modelo catequético, muy efectivo desde el periodo de la conquista hasta el siglo XX para la educación de los colombianos (Castrillón, 2012) en la actualidad se muestra anacrónico, porque aun cuando el país sigue siendo mayoritariamente cristiano, los educandos han dejado claro a través de sus representaciones sociales, la necesidad de abrir el espectro de la Educación Religiosa a la comprensión de la experiencia religiosa en sí misma más allá de un credo particular, por ello se debe hacer una apuesta por un giro epistemológico que considere como objeto de estudio de este saber escolar la experiencia religiosa, el hecho religioso, el fenómeno religioso y el desarrollo religioso (Meza-Rueda y Reyes-Fonseca, 2018), como bases para un propuesta de contexto.

En este sentido, las representaciones aquí descritas, se convierten en un punto de reflexión que motiva a pensar un nuevo modelo de Educación Religiosa que lleve al educando a la configuración de su identidad religiosa, la cual debe ser el fundamento para dar respuesta a la pregunta por el qué creer (Naranjo y Moncada, 2019), a la vez que le permite comprender la plural y compleja realidad religiosa local, nacional y global, para, desde ahí, entrar en diálogo con sus congéneres en términos de lo religioso pero también, estar en capacidad de entrar en relación con otras tradiciones religiosas en un ambiente de diversidad (Gamarra et al., 2019) y así tomar postura frente a las problemáticas religiosas 
contemporáneas que le circundan (Echeverry, 2012).

Desde lo expresado en el párrafo anterior, emerge el reto de plantear propuestas de Educación Religiosa de contexto, en las que se debe dar un lugar importante a los saberes del educando, por ello se indagó en los grupos de discusión por cómo ellos consideraban que debía ser su clase, a lo que respondieron que más que una catequesis, esperaban que esta fuera un espacio pedagógico cuyo objetivo debería centrase en la formación de la dimensión religiosa desde el cultivo de la espiritualidad y una orientación hacia lo sagrado, además de generar una conciencia de la influencia que tienen la religión en la vida del ser humano y las relaciones sociales (Restrepo, 2016); también se debe tener en cuenta que desde el abordaje de la cultura se debe fomentar la libertad religiosa, para la promoción del diálogo interreligioso, el diálogo de fe y el diálogo fe-vida y así permitir la búsqueda de sentido y la relación con el misterio para satisfacer la necesidad humana de autotrascendencia.

Para lograr lo anterior se plantean saberes como las preguntas fundamentales del hombre, el estudio de las religiones, las tradiciones religiosas y la relación religión-sociedad, los cuales se pueden articular en un dispositivo didáctico que permita su dinamización. Sin embargo, estos son sólo algunos elementos a tener en cuenta para hacer de la Educación Religiosa el saber escolar que permita responder a la pregunta del qué creer. Aún con lo aquí planteado, queda el gran desafío de encontrar caminos para armonizar este saber escolar desde los modelos de la dimensión religiosa y la cultura sin excluir lo propio, ya que no se trata de suprimir el sistema de creencias predominante sino de hacerlo entrar en relación crítica con la realidad de los educandos y la realidad social.

Finalmente, la red semántica (figura 3) presenta una tercera categoría que emergió en el trabajo de campo llamada problemáticas asociadas, estas últimas surgieron como una categoría emergente a partir de lo planteado en la investigación, sin embargo, sólo se dejaron mencionadas ya que de abordarlas podrían desbordar el objetivo propuesto, no obstante, los investigadores las dejan planteadas en este escrito porque, además de emerger en el trabajo de campo, estas se configuran como situaciones que no obedecen al planteamiento de la clase sino que se perfilan como elementos externos al espacio pedagógico, que terminan por condicionar de manera sensible su puesta en escena en el aula.

\section{Referencias}

Abric, J. (2001). Las representaciones sociales: aspectos teóricos. En J. Abric (Ed.), Prácticas sociales $y$ representaciones (pp.11-31). Ediciones Coyoacan. https://campus.fundec.org.ar/admin/archivos/ABRIC - $\quad$ practicas-sociales-yrepresentaciones-5-16.pdf 
Banchs, M. (2000). Aproximaciones procesuales y estructurales al estudio de las representaciones sociales. Paper on Social Social Representations, (9), 3.1-3.15. https://psr.iscte-iul.pt/index.php/PSR/article/view/269

Barragán, D. (2016). Cartografía social pedagógica: entre teoría y metodología. Revista Colombiana de Educación, 247-285 https://doi.org/10.17227/01203916.70rce247.285

Barragán, D., y Amador, J. (2014). La cartografía social- pedagógica: una oportunidad para producir conocimiento y re-pensar la educación. Itinerario Educativo, 28(64), 127-141. https://doi.org/10.21500/01212753.1422

Beltrán, R. (2018). Estado del arte sobre educación religiosa escolar (ere) en Colombia 2007 - 2018 [Trabajo de maestría, Universidad del Tolima]. Archivo digital. http://repository.ut.edu.co/handle/001/2566

Bordini, G., y Sperb, T. (2011). O uso dos grupos focais on-line síncronos em pesquisa qualitativa. Psicologia Em Estudo, 16(3), 437-445. https://doi.org/10.1590/S141373722011000300011

Castaño, B. (2018). Representaciones sociales sobre la educación religiosa en adolescentes con indentidad religiosa minoritaria [Trabajo de maestría, Tecnológico de Antioquia, Institución universitaria]. https://dspace.tdea.edu.co/handle/tda/389

Castorina, J., y Barreiro, A. (2012). Los usos de las representaciones sociales en la investigación educativa. Educación, Lenguaje y Sociedad, 9(9), 15-40. https://cerac.unlpam.edu.ar/index.php/els/article/view/1459/1474

Castrillón, J. (2012). Elementos históricos para una comprensión de la ERE en Colombia. En J. Meza (Ed.), Educación religiosa escolar. Naturaleza, fundamentos y perspectivas. (pp. 37-70). Ediciones San Pablo.

Coy, M. (2009). Educación religiosa escolar ¿Por qué y para qué? Franciscanum, 51(152), 49-70. https://doi.org/10.21500/01201468.953

Dorio, I., Massot, I., y Sabariego, M. (2009). Estrategias de recogida y análisis de la Información. En R. Bisquerra (Ed.), Metodología de la investigación esducativa (pp. 275-292). Editorial la Muralla.

Echeverri, A. (2012). Libertad religiosa y educación en Colombia: Ni intocables ni míticas. Revista Cientifica Guillermo de Ockham, 10(1), 123-134. https://doi.org/10.21500/22563202.2381

Eliade, M. (1999). Historia de las ideas y las creencias religiosas I De la edad de piedra a los misterios de Eleusis. Ediciones Paidós. 
Fuentes, R. (2014). Comunicación y doble hermenéutica: convergencias entre disciplinas científicas y profesiones. Matrizes, $8(2)$, 79-100. https://doi.org/10.11606/issn.19828160.v8i2p70-100

Gamarra, A., Genes, E. Y Pacheco, L. (2019). La Educación Religiosa escolar como espacio ecuménico y fundamento espiritual-humanizante. Assensus, 4(6), 70-89. https://doi.org/10.21897/assensus.1840

Hernández, R., Fernández, C. y Baptista, P. (2010). Metodología de la investigación. Mc Graw Gill Educación.

Jodelet, D. (2000). Representaciones sociales: contribución a un saber sociocultural sin fronteras. En D. Jodelet y A. Guerrero (Eds.), Develando la cultura. Estudios en representaciones sociales (pp. 7-30). Facultad de psicología UNAM.

Lonergan, B. (2006). Método en teología. Edicaciones Sígueme.

Meza-Rueda, J y Reyes-Fonseca, J. (2018). Pensar el objeto de estudio de la educación religiosa escolar. Revista Electrónica de Educación Religiosa, 8(2), 1-24. http://www.reer.cl/index.php/reer/article/view/82/73

Meza-Rueda, J., Suárez-Meza, G., Garavito, D., Lara, D., y Reyes, J. (2015). Educación Religiosa Escolar en perspectiva liberadora. Civilizar Ciencias Sociales y Humanpas, 15(28), 247-262. https://doi.org/10.22518/16578953.291

Meza, J. y Suarez, G. (2013). Educar para la libertad. Una propuesta de educación religiosa escolar en perspectiva liberadora. Editorial San Pablo.

Meza, J. (2012). Naturaleza, finalidad y legitimación de la ERE. En J. Meza (Ed.), Educación reigiosa escolar. Naturaleza, fundamentos y perspectivas. (pp. 13-36). Ediciones San Pablo.

Ministerio de Educación Nacional. (2014). Documento guía docente de básica secundaria y media educación religiosa: Evaluación de competencias para el ascenso o reubicación de nivel salarial en el Escalafón de Profesionalización Docente de los docentes y directivos docentes regidos por el Decreto ley 1278 de 2002. https://www.academia.edu/8345883/2014_DG03_DOCUMENTO_GU\%C3\%8DA

Moscovici, S. (1979). El psicoanálisis, su imagen y su público. Huemul.

Naranjo, S y Moncada, C. (2019). Aportes de la Educación Religiosa escolar al cultivo de la espiritualidad humana. Educación y Educadores, 22(1), 103-119. https://doi.org/10.5294/edu.2019.22.1.6

Pikaza, X. (1999). El fenómeno religioso. Trotta Editorial. 
Quintero, F. (2019). Representaciones sociales sobre la clase de educación religiosa escolar de los estudiantes de grado $11^{\circ}$ de dos instituciones educativas católicas de Bogotá y sus implicaciones en la construcción de una ERE pluralista [Trabajo de maestría, Universidad Santo Tomás].

Ricoy, C. (2006). Contribución sobre los paradigmas de investigación. Educação. Revista Do Centro de Educação, 31(1), 11-22. https://periodicos.ufsm.br/reveducacao/article/view/1486

Roa, L., y Restrepo, L. (2014). El currículo incluyente y diverso de la clase de religión en escuelas del Cauca, Colombia. Revista de Investigaciones UCM, 14(2), 98-109. https://doi.org/10.22383/ri.v14i2.25

Restrepo, L. (2016). Prácticas pedagógicas en contextos de pluralidad religiosa en Colombia. Pensamiento Educativo. Revista de Investigación Educacional Latinoamericana. 53(2), 1-14. https://doi.org/10.7764/pel.53.2.2016.4

Rossiter, G. (2010). Perspective on contemporary spirituality: Implications for religious education in Catholic schools. International Studies in Catholic Education, 2(2), 129147. https://doi.org/10.1080/19422539.2010.504019

Saavedra, J., y Tovar, V. (2015). Caracterísiticas de la Educación Religiosa Escolar (ERE) en las instituciones educativas de Ibagué [Trabajo de maestría, Universidad del Tolima]. http://repository.ut.edu.co/handle/001/1489

Sandoval, C. (1996). Investigación cualitativa. Especialización en teoría, métodos Y técnicas de investigación social. ARFO editores e impresiones

Sotomayor, E. (2003). Catequesis evangelizadora. Manual de catequética fundamental. Ediciones Abya-Yala.

Velasco, J. (2006). Introducción a la fenomenología de la religión. Editorial Trotta.

Villoro, L. (2007). El concepto de ideología y otros ensayos. FCE. 